\title{
Development Length Criteria for Conventional and High Relative Rib Area Reinforcing Bars
}
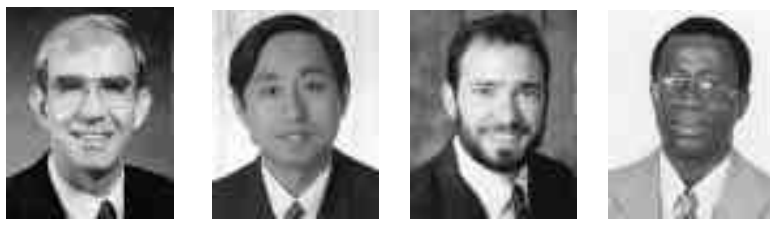

by David Darwin, Jun Zuo, Michael L. Tholen, and Emmanuel K. Idun

Statistical analyses of 133 splice and development specimens in which the bars are not confined by transverse reinforcement and 166 specimens in which the bars are confined by transverse reinforcement are used to develop an expression for the bond force at failure as a function of concrete strength, cover, bar spacing, development/splice length, transverse reinforcement, and the geometric properties of the developed/spliced bars. Results are used to formulate design criteria that incorporate a reliability-based strength reduction ( $\phi)$ factor that allows the calculation of a single value for both development and splice length for given material properties and member geometry.

As with earlier studies, the analyses demonstrate that the relationship between bond force and development or splice length $l_{d}$ is linear but not proportional. Thus, to increase the bond force (or bar stress) by a given percentage requires more than the percentage increase in $l_{d} f_{c}^{\prime 1 / 2}$ does not provide an accurate representation of the effect of concrete strength on bond strength over the full range of concrete strengths in use today; development/splice strengths are underestimated for low-strength concretes and overestimated for high-strength concretes. $f_{c}^{\prime 1 / 4}$ provides an accurate representation of the effect of concrete strength on bond strength for concretes with compressive strengths between 2500 and 16,000 psi (17 and $110 \mathrm{MPa}$ ). The most accurate representation of the effect of transverse reinforcement on bond strength obtained in the current analysis includes parameters that account for the number of transverse reinforcing bars that cross the developed/spliced bar, the area of the transverse reinforcement, the number of bars developed or spliced at one location, the relative rib area of the developed/spliced bar, and the size of the developed/spliced bar. The yield strength of transverse reinforcement does not play a role in the effectiveness of the transverse reinforcement in improving development/splice strength. Depending on the design expression selected, for conventional and high relative rib area bars that are not confined by transverse reinforcement, development lengths average 2 to 14 percent higher and splice lengths 12 to 22 percent lower than those obtained using ACI 318-95. For conventional reinforcing bars confined by transverse reinforcement, development lengths average 5 percent lower to 16 percent higher than those obtained using ACI 318-95, while splice lengths average 11 to 27 percent lower than those obtained using ACI 318-95. For high relative rib area reinforcing bars confined by transverse reinforcement, development lengths average 3 to 17 percent lower than those obtained using ACI 318-95, while splice lengths average 25 to 36 percent lower than those obtained using ACI 318-95. When confined by transverse reinforcement, high relative rib area bars require development and splice lengths that are 13 to 16 percent lower than required by conventional bars.

Keywords: bond (concrete to reinforcement); bridge specifications; building codes; deformed reinforcement; development; lap connections; reinforcing steels; relative rib area; reliability; splicing; structural engineering.
The provisions in Chapter 12 of the 1995 ACI Building Code (ACI 318-95) will make the design process easier and reflect development and splice strength better than any previous code procedures. The new expressions are based, in part, on a statistical analysis carried out over 20 years ago (Orangun, Jirsa, and Breen 1975) and on recommendations based on that analysis provided by ACI Committee 408 (1990). As with previous versions of the ACI Code, the calculated development/splice lengths are proportional to the bar stress (the actual relationship is linear but not proportional), and most splice lengths are 30 percent greater than the corresponding development lengths.

Over the past 20 years, additional data has become available, and analyses of the expanded database (presented in this paper) have exposed a number of shortcomings in the ability of both the code expressions and the original statistically-based expressions to accurately represent the development and splice strength of reinforcing bars, as used in current practice. Specifically, the analyses demonstrate that the square root of the concrete compressive strength $f_{c}^{\prime}$ does not accurately characterize the effect of concrete strength on bond strength for the full range of concrete strengths in use today, and the yield strength of transverse reinforcement $f_{y t}$ plays no measurable role in the contribution of confining steel to bond strength. In addition, the study by Orangun et al. (1975, 1977) and a more recent study by Darwin, McCabe, Idun, and Schoenekase (1992a, 1992b) have the drawback of inadvertently including top-cast and side-cast bar specimens in analyses representing bottom-cast reinforcement. Only bottom-cast bars are considered in the current study.

The current analyses were carried out in conjunction with a large-scale experimental study to improve the development characteristics of reinforcing bars (Darwin and Graham

ACI Structural Journal, V. 93, No. 3, May-June 1996

Received Feb. 6, 1996, and reviewed under Institute publication policies. Copyright (C) 1996, American Concrete Institute. All rights reserved, including the making of copies unless permission is obtained from the copyright proprietors. Pertinent discussion will be published in the March-April 1997 ACI Structural Journal if received by Nov. 1, 1996. 
David Darwin, FACI, is the Deane E. Ackers Professor of Civil Engineering and Director of the Structural Engineering and Materials Laboratory at the University of Kansas. He is a past member of the Board of Direction and the Technical Activities Committee and is a past-president of the ACI Kansas Chapter. Darwin is Chairman of the Publications Committee, past-chairman of the Concrete Research Council, and a member and past-chairman of ACI Committee 224, Cracking. He is also a member of ACI Committees 408, Bond and Development of Reinforcement; 446, Fracture Mechanics; and ACI-ASCE Committees 445, Shear and Torsion, and 447, Finite Element Analysis of Reinforced Concrete Structures. He is a recipient of the Arthur R. Anderson Award and the ACI Structural Research Award.

ACI member Jun Zuo is a graduate research assistant in civil engineering at the University of Kansas. He obtained his BS in architectural engineering from Tongji University in China and his MS in civil engineering from the University of Kansas. He is currently pursuing his PhD degree.

ACI member Michael L. Tholen is a graduate research assistant in civil engineering at the University of Kansas, where he holds a BS in architectural engineering and an $M S$ in civil engineering. He is currently pursuing his PhD degree.

ACI member Emmanuel K. Idun is a lead structural engineer with Constructive Engineering Design, Kansas City, Missouri. He holds a BScEng in civil engineering and an MPhil in structures from the University of Science and Technology in Ghana, and a PhD from the University of Kansas.

1993a, 1993b, Darwin, Tholen, Idun, and Zuo 1995a, 1996a) and have several advantages over the earlier studies: 1) the database is larger (Chinn et al. 1955, Chamberlin 1956, 1958, Mathey and Watstein 1961, Ferguson and Thompson 1965, Ferguson and Breen 1965, Thompson et al. 1975, Zekany et al. 1981, Choi et al. 1990, 1991, DeVries et al. 1991, Hester et al. 1991, 1993, Rezansoff et al. 1991, 1993, Azizinamini et al. 1993, 1995, Darwin et al. 1995a, 1996a), including 133 splice and development specimens in which the bars are not confined by transverse reinforcement and 166 specimens in which the bars are confined by transverse reinforcement; 2) the concrete strengths cover a broader range than used in the earlier studies; and 3) data includes bars with a wide range of relative rib area (ratio of bearing area of ribs to shearing area between ribs) $R_{r}$, a parameter that has been demonstrated to significantly affect the added bond strength provided by transverse reinforcement (Darwin and Graham 1993a, 1993b, Darwin et al. 1995a, 1996a).

This paper describes the development of a statisticallybased expression that accurately represents the development and splice strength of reinforcing bars, both with and without confining reinforcement, for values of ${f_{c}^{\prime}}_{c}$ between 2500 and $16,000 \mathrm{psi}(17$ and $110 \mathrm{MPa})$. In addition to transverse reinforcement and concrete strength, the expression takes into account cover, bar spacing, development/splice length, and the geometric properties of the developed/spliced bars. The expression is used to formulate design criteria that incorporate a reliability-based strength reduction $(\phi)$ factor (Darwin, Idun, Zuo, and Tholen 1995c, 1996b) that allows the calculation of a single value for both splice and development length for given material properties and member geometry. Compared to current design practice (ACI 318-95, AASHTO Highway 1992), the new design criteria permit major reductions in the development lengths of high relative rib area bars confined by transverse reinforcement and in the splice lengths of conventional and high relative rib area bars under all conditions of confinement. Additional details of the study are presented by Darwin, Zuo, Tholen and Idun (1995b).

\section{OVERVIEW}

The statistical analyses and development of design criteria that are described in this paper are based on a model in which the maximum bond force in a developed or spliced bar $T_{b}$ is expressed as the sum of a "concrete contribution" $T_{c}$, which is a function of concrete strength, member geometry, and bar size, and a "steel contribution" $T_{s}$, which is a function of concrete strength, the geometric properties of the developed/ spliced bar, and the geometry of the confining reinforcement in the development/splice region

$$
T_{b}=T_{c}+T_{s}
$$

Eq. (1) serves as the basis of the analysis that, when complete, is used to formulate design expressions that are used to calculate development/splice length $l_{d}$.

The calculation of the concrete contribution $T_{c}$ builds on earlier work (Orangun et al. 1975, 1977, Darwin et al. 1992a, 1992b). The analysis initially proceeds by determining the best statistical match between the total bond force for bars not confined by transverse reinforcement $T_{c}=A_{b} f_{s}$, in which $A_{b}=$ bar area and $f_{s}=$ bar stress at development or splice failure, and the product of $l_{d}$, the development or splice length, and $c_{m}+0.5 d_{b}$, the smaller of the cover to the center of the bar $\left(c_{b}+0.5 d_{b}\right)$ or half the center-to-center bar spacing $\left(c_{s}+\right.$ $0.5 d_{b}$ ), in which $c_{b}=$ cover, $c_{s}=$ one-half of the clear spacing between bars, and $d_{b}=$ bar diameter. Next, adjustments are made to take into account the fact that bond strength increases with respect to the product $l_{d}\left(c_{m}+0.5 d_{b}\right)$ as the difference between $c_{b}$ and $c_{s}$ increases.

The initial analysis is carried out using (as is traditional) $f_{c}^{\prime 1 / 2}$ to represent the effect of concrete strength on bond strength. The resulting expression is tested for $f_{c}^{\prime}$ between 2610 and $15,120 \mathrm{psi}$ (18 and $104 \mathrm{MPa}$ ), and the power of $f_{c}^{\prime}$ is adjusted to provide an improved representation for bond strength. The new expression for $T_{c}$ is then used to calculate the steel contribution $T_{s}$ in development/splice tests for members containing confining reinforcement. This is done by subtracting the calculated value of the concrete contribution from the experimental bond force $T_{b}$

$$
T_{s}=T_{b}-T_{c}
$$

$T_{s}$ is correlated with the concrete strength, the geometric properties of the transverse reinforcement, and the geometric properties of the developed/spliced bars to obtain an accurate representation of the increase in bond strength provided by the confining steel. The evaluation includes the establishment of limits within which the expressions give conservative predictions of strength.

The resulting expressions for bond force for developed/ spliced bars, both with and without confining reinforcement, are then combined with a reliability-based strength reduction ( $\phi)$ factor (Darwin et al. 1995c, 1996b) to obtain design expressions for $l_{d}$. The expressions include the effect of relative rib area $R_{r}$, and thus, can be used to take advantage of the increased bond strength obtainable with high $R_{r}$ bars. The development and splice lengths obtained with the new 
expressions are then compared to those obtained using ACI 318-95.

Test specimens used in the analyses are limited to splice and development specimens for which concrete properties are characterized by the compressive strength of standard cylinders (ASTM C 39).

\section{EXPRESSIONS FOR DEVELOPMENT/SPLICE STRENGTH}

\section{Bars without confining reinforcement}

The work reported herein represents the final results of a series of analyses using 133 development and splice specimens containing bottom-cast bars.

Using $f_{c}^{\prime}{ }^{1 / 2}$ to represent the effect of concrete compressive strength on bond strength produces the following expression for total bond force for bars not confined by transverse reinforcement

$$
\begin{aligned}
& \frac{T_{c}}{f_{c}^{\prime 1 / 2}}=\frac{A_{b} f_{s}}{f_{c}^{\prime 1 / 2}}=\left[8.76 l_{d}\left(c_{m}+0.5 d_{b}\right)\right. \\
& \left.+187 A_{b}\right]\left(0.14 \frac{c_{M}}{c_{m}}+0.86\right)
\end{aligned}
$$

in which

$c_{m}, c_{M}=$ minimum and maximum value of $c_{s}$ or $c_{b}\left(c_{M} / c_{m} \leq\right.$ $3.5)$, in in.

$c_{s}=\min \left(c_{s i}+0.25\right.$ in., $\left.c_{s o}\right)$, in.

$c_{s i}=$ one-half of clear spacing between bars, in.

$c_{s o}, c_{b}=$ side cover and bottom cover of reinforcing bars, in. $T_{c}$ is in lb, $A_{b}$ is in in. ${ }^{2}$, and $f_{s}, f_{c}^{\prime}$, and $f_{c}^{\prime}{ }_{c}^{1 / 2}$ are in psi.

Eq. (3) is obtained following the procedures of Darwin et al. (1992a, 1992b). A best-fit is obtained between $T_{c} / f_{c}^{\prime 1 / 2}$ and the product $l_{d}\left(c_{m}+0.5 d_{b}\right)$ using a dummy variable analysis (Draper and Smith, 1981) in which the data are separated based on bar size. The results of the analysis are then used to improve the fit by including a weighted average coefficient to represent the area of the bar $A_{b}$. Unlike the earlier analysis (Darwin et al. 1992a, 1992b), the effects of the differences in $c_{m}$ and $c_{M}$ are evaluated after the coefficient for $A_{b}$ is obtained.

The term $\left(0.14 c_{M} / c_{m}+0.86\right)$ is obtained based on a bestfit analysis comparing the test/prediction ratios [obtained using the term in brackets on the right side of Eq. (3) as the predicted strength] with the ratio $c_{M} / c_{m}$. The term takes into account the increased strength observed in the tests when $c_{m}$ $\neq c_{M}$. When determining $c_{s}, 0.25$ in. $(6 \mathrm{~mm})$ is added to $c_{s i}$, one-half of the clear spacing between the bars, because the extra 0.25 in. $(6 \mathrm{~mm})$ gives an improved match with the test data. The fact that the effective value of $c_{s i}$ is slightly larger than one-half of the clear spacing is likely due to the longer effective crack lengths that occur when concrete splits between the bars rather than through the cover (Darwin et al. 1992a, 1992b).

When the test results used to develop Eq. (3) are re-evaluated based on categories of concrete strength, the specimens with the lowest strength concretes produce the highest relative strengths, as shown in Fig. 1. For the categories of concrete strengths evaluated, from below 3000 to over $10,000$ psi (21 to $69 \mathrm{MPa})$, the intercepts on the vertical axis decrease as the concrete strength increases. The line representing concrete with compressive strengths above 10,000 psi $(69 \mathrm{MPa})$ is significantly below that of the rest of the data. The comparisons show that $f^{\prime}{ }_{c}^{1 / 2}$ gives a good representation for concrete strengths between 4500 and 7500 psi (31 and $52 \mathrm{MPa}$ ). Outside of this range, $f_{c}^{\prime}{ }^{1 / 2}$ does not give a good representation.

Based on this observation, a series of reanalyses were carried out to determine the power of $f_{c}^{\prime}$ that would minimize the spread in the data. The reanalyses showed that $f^{\prime}{ }_{c}$ to the 0.24 power provided the best match. For obvious reasons of convenience, the $1 / 4$ power was selected for further analysis.

Using the $1 / 4$ power, the best-fit equation is

$$
\begin{aligned}
\frac{T_{c}}{f_{c}^{\prime 1 / 4}}=\frac{A_{b} f_{s}}{f_{c}^{\prime 1 / 4}}= & {\left[63 l_{d}\left(c_{m}+0.5 d_{b}\right)+2130 A_{b}\right] } \\
& \left(0.1 \frac{c_{M}}{c_{m}}+0.9\right)
\end{aligned}
$$

in which $f_{c}^{\prime 1 / 4}$ is in psi.

As illustrated in Fig. 2, Eq. (4) produces significantly less scatter as a function of compressive strength than Eq. (3). The best-fit lines for all categories of concrete strength nearly coincide, with the exception of the specimens with concrete strengths in excess of 10,000 psi (69 MPa). This deviation is largely the result of the limited amount of data for development/splice tests using high-strength concrete. Two relatively low splice strengths have a dominant effect on the results for this category. If those two tests are removed, all strength categories produce nearly coincident best-fit lines (Darwin et al. 1995b).

Table 1 provides a summary of the test/prediction ratios for the 133 specimens used to develop Eq. (3) and (4). As shown in the table, the mean test/prediction ratio for the 133 specimens without transverse reinforcement is 1.00 using both the $1 / 2$ [Eq. (3)] and the $1 / 4$ [Eq. (4)] power of $f_{c}^{\prime}$, with a coefficient of variation (COV) of 0.138 using the $1 / 2$ power of $f_{c}^{\prime}$ and a COV of 0.107 using the $1 / 4$ power. The individual comparisons are presented by Darwin et al. (1995b) and in Appendix A.*

\section{Bars with confining reinforcement}

Eq. (2) is used to determine the additional bond strength provided by transverse reinforcement $T_{s}$. The concrete contribution to bond strength $T_{c}$, given in Eq. (4), is subtracted from the experimental bond force $T_{b}$. The results for 166 specimens in which the developed/spliced bars were confined by transverse reinforcement were initially used for this analysis. During the course of the analysis, it was established that especially low strengths, with respect to any predictive equations, were exhibited by specimens with $l_{d} / d_{b}<16$. Therefore, 32 specimens with $l_{d} / d_{b}<16$ have been removed

*The Appendix is available in xerographic or similar form from ACI headquarters, where it will be kept permanently on file, at a charge equal to the cost of reproduction plus handling at time of request. 


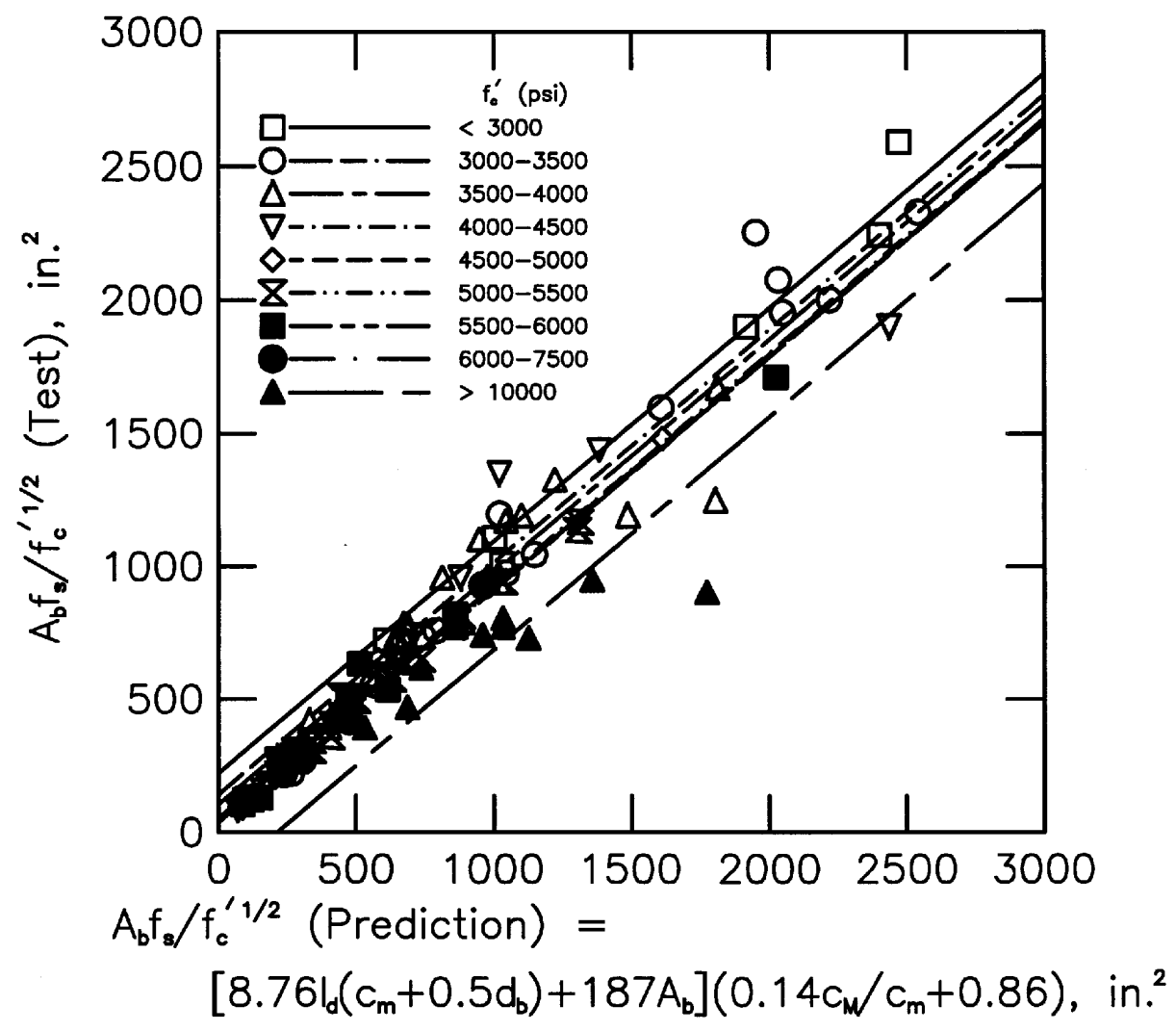

Fig. 1-Experimental bond force $T_{c}=A_{b} f_{s}$ normalized with respect to $f_{c}^{\prime 1 / 2}$ versus predicted bond force $A_{b} f_{s} / f_{c}^{\prime 1 / 2}$, as a function of concrete compressive strength for bars without confining reinforcement

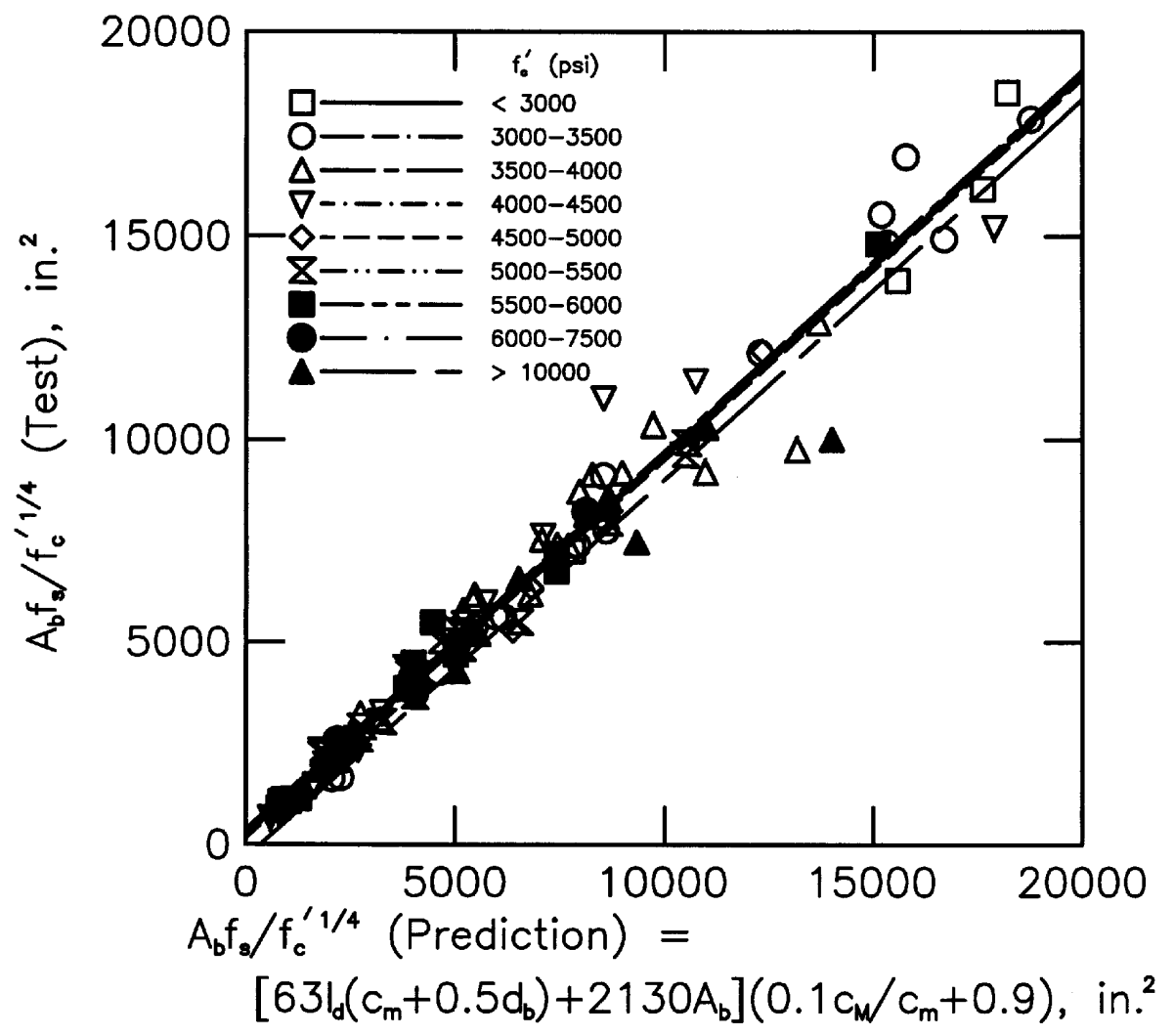

Fig. 2-Experimental bond force $T_{c}=A_{b} f_{s}$ normalized with respect to $f_{c}^{\prime}{ }^{1 / 4}$ versus predicted bond force $A_{b} f_{s} / f_{c}^{\prime 1 / 4}$ as a function of concrete compressive strength for bars without confining reinforcement 
from the analysis, leaving 134 specimens for the following analysis. The removal of these specimens does not hurt the overall evaluation, since members with such low values of $l_{d} / d_{b}$ are not used in practice.

Correlations of $T_{s}$ with several combinations of potential controlling parameters are evaluated. Principal among these parameters are the yield strength of the transverse reinforcement $f_{y t}$ and the effective area of transverse reinforcement per developed/spliced bar $N A_{t r} / n$, in which $N=$ the number of transverse reinforcing bars (stirrups or ties) crossing $l_{d} ; A_{t r}$ $=$ area of each stirrup or tie crossing the potential plane of splitting adjacent to the reinforcement being developed or spliced, and $n=$ number of bars being developed or spliced along the plane of splitting. The value of $n$ is determined by the smaller of $c_{b}$ or $c_{s}$. If $c_{b}$ controls, the plane of splitting passes through the cover and $n=1$. If $c_{s}$ controls, the plane of splitting intersects all of the bars and $n=$ the total number of bars spliced or developed at one location. Also included in the analysis are parameters $t_{r}$ and $t_{d}$, representing the effects of the relative rib area and bar size, respectively, of the developed/spliced bar on $T_{s}$

$$
\begin{gathered}
t_{r}=9.6 R_{r}+0.28 \\
t_{d}=0.72 d_{b}+0.28
\end{gathered}
$$

Eq. (5) and (6) are based on an analysis of test results for 70 splice specimens containing No. 5, No. 8, and No. 11 (16, $25,36-\mathrm{mm}$ ) bars confined by transverse reinforcement with relative rib areas $R_{r}$ ranging from 0.065 to 0.14 . Details of the development of Eq. (5) and (6) are presented by Darwin et al. (1995a, 1996a). For conventional reinforcement, $t_{r}$ typi- cally ranges from 0.82 to 1.11 (for $R_{r}$ from 0.056 to 0.086 ), with an average value of 0.98 [for the average value of $R_{r}=$ 0.0727 (Darwin et al. 1995b)]; $t_{d}=0.73,1.00$, and 1.295 for No. 5, No. 8, and No. 11 (16, 25, 36-mm) bars, respectively.

To determine the principal controlling parameters, $T_{s}$ is compared to four combinations of the parameters; $N A_{t r} f_{y l} / n$, $N A_{t r} / n, t_{r} N A_{t r} / n$, and $t_{r} t_{d} N A_{t r} / n$. The first of these variables, $N A_{t r} f_{y t} / n$, is incorporated in ACI 318-95 to represent the effect of confining reinforcement on bond strength (in ACI 318-95, $N=l_{d} / s$, in which $s=$ spacing of transverse reinforcement).

In carrying out the analyses, distinct differences are observed in the test results for different investigators. For example, the bond strengths obtained by Rezansoff et al. (1991, 1993) are consistently higher than those obtained by Choi et al. (1990, 1991), Hester et al. (1991, 1993), and Darwin et al. (1995a, 1996a). The differences, in all likelihood, are due to differences in concrete properties and, perhaps, testing procedures. The effect of concrete properties on bond strength is demonstrated by Darwin et al. (1995a, 1996a), who observed 35 to 45 percent changes in the effectiveness of transverse reinforcement with a change in coarse aggregate. To remove the variation caused by differences in concrete properties or other differences between test sites, the study uses a dummy variables analysis in which the data is separated based on test site and bar size.

Of the 134 specimens used in the analysis, the value of $R_{r}$ is known for 85 specimens, based on measurements made on the bars or based on data provided in the original papers. For the balance of the bars, the mean values of $R_{r}$ for bars of that size are used. The mean values, 0.0752 for No. 5 (16-mm) bars, 0.0748 for No. 6 (19-mm) bars, 0.0731 for No. 8 (25$\mathrm{mm})$ bars, and 0.0674 for No. 11 (36- $\mathrm{mm})$ bars, are based on bar samples measured in studies dating to 1987 (Choi et al.

\begin{tabular}{|c|c|c|c|c|c|c|c|}
\hline Specimen type & $\begin{array}{c}\text { Number of } \\
\text { specimens }\end{array}$ & $\begin{array}{l}\text { Power of } f_{c}^{\prime} \\
\text { (Eq.) }\end{array}$ & Minimum & Maximum & Mean & $\begin{array}{l}\text { Standard } \\
\text { deviation }\end{array}$ & $\begin{array}{l}\text { Coeffi- } \\
\text { cient of } \\
\text { variation }\end{array}$ \\
\hline $\begin{array}{l}\text { Without transverse } \\
\text { reinforcement }\end{array}$ & 133 & $\begin{array}{l}1 / 2 \text { [Eq. (3)] } \\
1 / 4 \text { [Eq. (4)] }\end{array}$ & $\begin{array}{l}0.509 \\
0.716\end{array}$ & $\begin{array}{l}1.325 \\
1.290\end{array}$ & $\begin{array}{l}1.000 \\
1.003\end{array}$ & $\begin{array}{l}0.138 \\
0.107\end{array}$ & $\begin{array}{l}0.138 \\
0.107\end{array}$ \\
\hline $\begin{array}{l}\text { Without transverse } \\
\text { reinforcement, } f_{s}>f_{y}\end{array}$ & 11 & $\begin{array}{l}1 / 2 \text { [Eq. (3)] } \\
1 / 4 \text { [Eq. (4)] }\end{array}$ & $\begin{array}{l}0.783 \\
0.854\end{array}$ & $\begin{array}{l}1.213 \\
1.275\end{array}$ & $\begin{array}{l}0.968 \\
0.992\end{array}$ & $\begin{array}{l}0.112 \\
0.107\end{array}$ & $\begin{array}{l}0.115 \\
0.107\end{array}$ \\
\hline $\begin{array}{l}\text { With transverse } \\
\text { reinforcement }\end{array}$ & 166 & $1 / 4$ [Eq. (17)] & 0.571 & 1.387 & 0.979 & 0.138 & 0.141 \\
\hline $\begin{array}{c}\text { With transverse } \\
\text { reinforcement, } \\
l_{d} / d_{b} \breve{S} S \breve{S} \breve{S} S \geq 16\end{array}$ & 134 & 1/4 [Eq. (17)] & 0.664 & 1.352 & 0.989 & 0.135 & 0.137 \\
\hline $\begin{array}{l}\text { With transverse rein- } \\
\text { forcement, } l_{d} / d_{b} \\
\text { ŠŠŠŠS } \breve{S} \geq 16,(c+ \\
\left.K_{t r}\right) / d_{b} \leq 4^{*}\end{array}$ & $119^{\dagger}$ & 1/4 [Eq. (17)] & 0.770 & 1.352 & 1.010 & 0.127 & 0.125 \\
\hline $\begin{array}{l}\text { With transverse rein- } \\
\text { forcement, } f_{s}>f_{y}, \\
l_{d} / d_{b} \breve{S} \breve{S} \breve{S} \breve{S} \geq 16, \\
\left(c+K_{t r}\right) / d_{b} \leq 4^{*}\end{array}$ & 20 & 1/4 [Eq. (17)] & 0.931 & 1.352 & 1.153 & 0.154 & 0.134 \\
\hline $\begin{array}{l}\text { With transverse rein- } \\
\text { forcement, } f_{s}>f_{y} \text {, } \\
l_{d} / d_{b} \breve{\mathrm{S}} \breve{S} \breve{S} \mathrm{~S} \geq 16, \\
\left(c+K_{t r}\right) / d_{b} \leq 4^{*}\end{array}$ & 99 & 1/4 [Eq. (17)] & 0.770 & 1.261 & 0.981 & 0.098 & 0.100 \\
\hline
\end{tabular}

Table 1-Summary of test/prediction ratios for developed and spliced bars 
1990, 1991, Hester et al. 1991, 1993, Darwin et al. 1995a), including bar samples provided by other researchers (Rezansoff et al. 1991, 1993, Azizinamini et al. 1995). The overall average value of $R_{r}, 0.0727$, represents No. 5 and larger bars. $R_{r}$ $=0.0727$ is used for bar sizes other than No. 5 , No. 6 , No. 8 , and No. $11(16,19,25,36 \mathrm{~mm})$, if individual data is not available. For "metric bars" (Rezansoff et al. 1991, 1993), nominal metric sizes are converted exactly to customary units for the analysis. For the analysis, $T_{s}$ is in $\mathrm{lb}, f_{y t}, f_{c}^{\prime}$ and $f_{c}^{\prime}{ }^{1 / 4}$ are in psi, and $A_{t r}$ is in in. ${ }^{2}$ The database includes specimens with concrete strengths between 1820 and 15,760 psi (13 and $109 \mathrm{MPa}$ ) and bars with relative rib areas between 0.059 and 0.14 .

Based on the dummy variables analyses and using the weighted mean intercepts at $T_{s} / f_{c}^{\prime}{ }^{1 / 4}=0$, the best-fit expressions for the four combinations are

$$
\frac{T_{s}}{f_{c}^{\prime 1 / 4}}=26.7 \frac{N A_{t r} f_{y t}}{n}+355
$$

with a coefficient of determination $r^{2}=0.757$.

$$
\frac{T_{s}}{f_{c}^{\prime 1 / 4}}=2391 \frac{N A_{t r}}{n}+89
$$

with $r^{2}=0.787$.

$$
\frac{T_{s}}{f_{c}^{\prime 1 / 4}}=2093 t_{r} \frac{N A_{t r}}{n}+110
$$

with $r^{2}=0.840$.

$$
\frac{T_{s}}{f_{c}^{\prime 1 / 4}}=1867 t_{r} t_{d} \frac{N A_{t r}}{n}+177
$$

with $r^{2}=0.839$.

The closer the coefficient of determination $r^{2}$ is to 1.0 , the better the correlation between $T_{s} / f_{c}^{\prime 1 / 4}$ and the selected combination of parameters. $r^{2}$ is lowest $(0.757)$ when $N A_{t r} f_{y t} / n$ is used to represent the effect of transverse reinforcement on bond strength [Eq. (7)]. Removal of $f_{y t}$ from the controlling variable [Eq. (8)] improves $r^{2}$ to 0.787 . The fact that such an improvement would occur makes sense, since it has been demonstrated that transverse reinforcement rarely yields during a splice or development failure (Maeda et al. 1991, Sakurada et al. 1993, Azizinamini et al. 1995). The addition of $t_{r}$ to the analysis [Eq. (9)], as supported by the experimental work of Darwin et al. (1995a, 1996a), improves $r^{2}$ to 0.840 , while the addition of $t_{d}$ [Eq. (10)], also supported by Darwin et al. (1995a, 1996a), drops $r^{2}$ slightly to 0.839. For reasons that will be clear shortly, Eq. (10) is used for the next step in the analysis.

Combining Eq. (4) and Eq. (10), replacing $N$ by $l_{d} / s$, dropping the mean intercept of 177 , and solving for the development/splice length $l_{d}$ gives

$$
l_{d}=\frac{A_{b}\left\lfloor\frac{f_{s}}{f_{c}^{\prime 1 / 4}}-2130\left(0.1 \frac{c_{M}}{c_{m}}+0.9\right)\right\rfloor}{63\left[\left(c_{m}+0.5 d_{b}\right)\left(0.1 \frac{c_{M}}{c_{m}}+0.9\right)+\frac{29.6 t_{r} t_{d} A_{t r}}{s n}\right]}
$$

Modifying Eq. (11) to express $l_{d}$ in terms of bar diameter $d_{b}$ gives

$$
\frac{l_{d}}{d_{b}}=\frac{\frac{f_{s}}{f_{c}^{\prime 1 / 4}}-2130\left(0.1 \frac{c_{M}}{c_{m}}+0.9\right)}{80.2\left(\frac{c+K_{t r}}{d_{b}}\right)}
$$

in which $c=\left(c_{m}+0.5 d_{b}\right)\left(0.1 c_{M} / c_{m}+0.9\right)$ and $K_{t r}=29.6$ $t_{r} t_{d} A_{t r} / s n$.

$\left(c+K_{t r}\right) / d_{b}$ in the denominator of Eq. (12) is a measure of the assistance provided by concrete cover, bar spacing, and transverse reinforcement (ACI 318-95), increases that result in an increase in bond strength. Increases in $\left(c+K_{t r}\right) / d_{b}$, however, will eventually cause the mode of bond failure to switch from splitting to pullout, with bond strength limited by the strength of the concrete between the ribs of the bar rather than the clamping forces provided by surrounding concrete and steel. When this happens, bond strengths will drop in relation to the predicted strength.

Test/prediction ratios, based on the sum of Eq. (4) and (10), are compared with $\left(c+K_{t r}\right) / d_{b}$ for the 134 tests with $l_{d} /$ $d_{b} \geq 16$ in Fig. 3 . The figure shows that the test/prediction ratios are consistently below 1.0 for values of $\left(c+K_{t r}\right) / d_{b}>$ 3.75. Based on this observation, a reanalysis was carried out using specimens with $\left(c+K_{t r}\right) / d_{b} \leq 3.75$.

Based on the dummy variables analysis for the remaining 119 specimens and using the weighted mean intercepts at $T_{s} /$ $f_{c}^{\prime}{ }^{1 / 4}=0$, the best-fit expressions for the four combinations are

$$
\frac{T_{s}}{f_{c}^{\prime 1 / 4}}=30.3 \frac{N A_{t r} f_{y t}}{n}+430
$$

with $r^{2}=0.758$

$$
\frac{T_{s}}{f_{c}^{\prime 1 / 4}}=2521 \frac{N A_{t r}}{n}+148
$$

with $r^{2}=0.783$

$$
\frac{T_{s}}{f_{c}^{\prime \prime 1 / 4}}=2412 t_{r} \frac{N A_{t r}}{n}+71
$$

with $r^{2}=0.853$.

$$
\frac{T_{s}}{f_{c}^{\prime 1 / 4}}=2226 t_{r} t_{d} \frac{N A_{t r}}{n}+66
$$


with $r^{2}=0.857$

In this case, $t_{r} t_{d} N A_{t r} / n$ [Eq. (16)] provides the best coefficient of determination and the lowest intercept. Combining Eq. (16) with Eq. (4) gives the final expression for $T_{b}$

$$
\begin{aligned}
& \frac{T_{b}}{f_{c}^{\prime 1 / 4}}=\frac{T_{c}+T_{s}}{f_{c}^{\prime 1 / 4}}=\frac{A_{b} f_{s}}{f_{c}^{\prime 1 / 4}}=\left[63 l_{d}\left(c_{m}+0.5 d_{b}\right)\right. \\
& \left.+2130 A_{b}\right]\left(0.1 \frac{c_{M}}{c_{m}}+0.9\right)+2226 t_{r} t_{d} \frac{N A_{t r}}{n}+66
\end{aligned}
$$

Dropping the intercept 66 and solving for $l_{d}$ in terms of $A_{b}$ and $d_{b}$ gives, respectively,

$$
\begin{gathered}
l_{d}=\frac{A_{b}\left\lfloor\frac{f_{s}}{f_{c}^{\prime 1 / 4}}-2130\left(0.1 \frac{c_{M}}{c_{m}}+0.9\right)\right\rfloor}{63\left[\left(c_{m}+0.5 d_{b}\right)\left(0.1 \frac{c_{M}}{c_{m}}+0.9\right)+\frac{35.3 t_{r} t_{d} A_{t r}}{s n}\right]} \\
\frac{l_{d}}{d_{b}}=\frac{\frac{f_{s}}{f_{c}^{\prime 1 / 4}}-2130\left(0.1 \frac{c_{M}}{c_{m}}+0.9\right)}{80.2\left(\frac{c+K_{t r}}{d_{b}}\right)}
\end{gathered}
$$

in which $c=\left(c_{m}+0.5 d_{b}\right)\left(0.1 c_{M} / c_{m}+0.9\right)$ and $K_{t r}=35.3$ $t_{r} t_{d} A_{t r} / s n$. Eq. (19) and (12) are identical, except for the coefficient in $K_{t r}$.
A reanalysis of the data versus $\left(c+K_{t r}\right) / d_{b}$ using Eq. (17) and the new definition of $K_{t r}$ is shown in Fig. 4, illustrating that Eq. (17) through (19) provide accurate predictions for specimens with $\left(c+K_{t r}\right) / d_{b} \leq 4.0$. A summary of the test/prediction ratios for all 166 specimens with transverse reinforcement in the database $\left(c / d_{b}=1.33\right.$ to $4.46, K_{t r} / d_{b}=0.12$ to 3.24) are presented in Table 1. For the 119 specimens used to develop Eq. (17) $\left(c / d_{b}=1.33\right.$ to $2.64, K_{t} / d_{b}=0.12$ to $2.55)$, the mean test/prediction ratio is 1.01 , with a COV of 0.125 ; two of the specimens have $\left(c+K_{t r}\right) / d_{b}>4.0$ (see Table 1). A comparison of the test results with the values predicted using Eq. (17) for the 117 specimens with $l_{d} / d_{b} \geq 16$ and $(c+$ $\left.K_{t r}\right) / d_{b} \leq 4.0$ (using $K_{t r}=35.3 t_{r} t_{d} A_{t r} / s n$ ) is shown in Fig. 5 (for completeness, it is noted that $c / d_{b}$ ranges from 1.33 to 3.44 for the specimens without confining reinforcement summarized in 1). Data on the individual comparisons is presented by Darwin et al. (1995b) and in Appendix A.*

\section{Effect of bar stress on development/splice strength}

Concern has been expressed that yielding of developed/ spliced bars will result in a reduction in bond strength (Orangun et al. 1975, Harajli 1994). An evaluation of the test results used in the current study shows that the concern is unwarranted.

Of the 133 test specimens without confining reinforcement, bars yielded in 11 specimens prior to bond failure. As shown in Table 1, the mean test/prediction ratio based on

*The Appendix is available in xerographic or similar form from ACI headquarters, where it will be kept permanently on file, at a charge equal to the cost of reproduction plus handling at time of request.

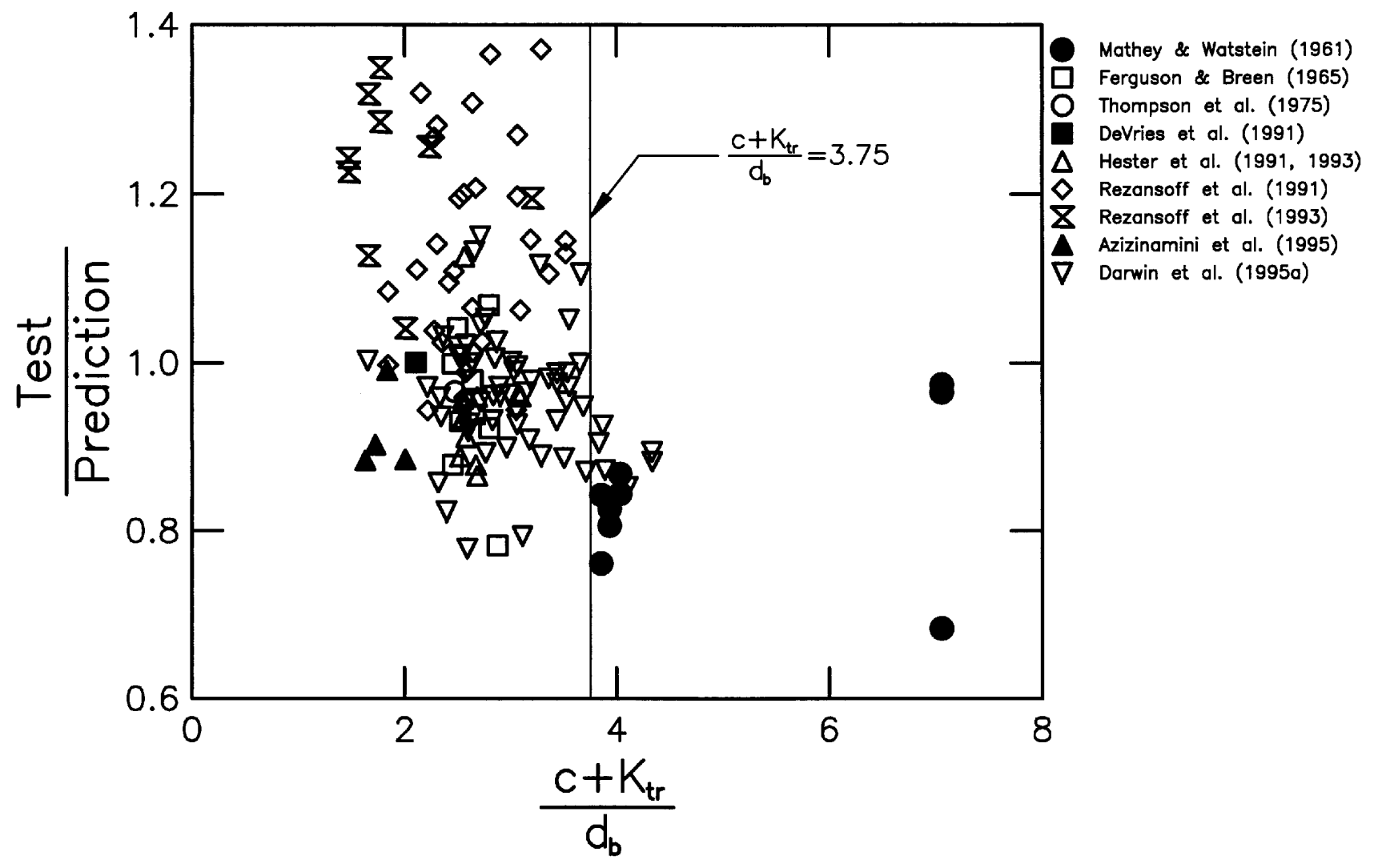

Fig. 3-Test/prediction ratio versus $\left(c+K_{t r}\right) / d_{b}$ for 134 beams with $l_{d} / d_{b} \geq 16\left(K_{t r}=29.6 t_{r} t_{d} A_{t r} / s n\right)$ 


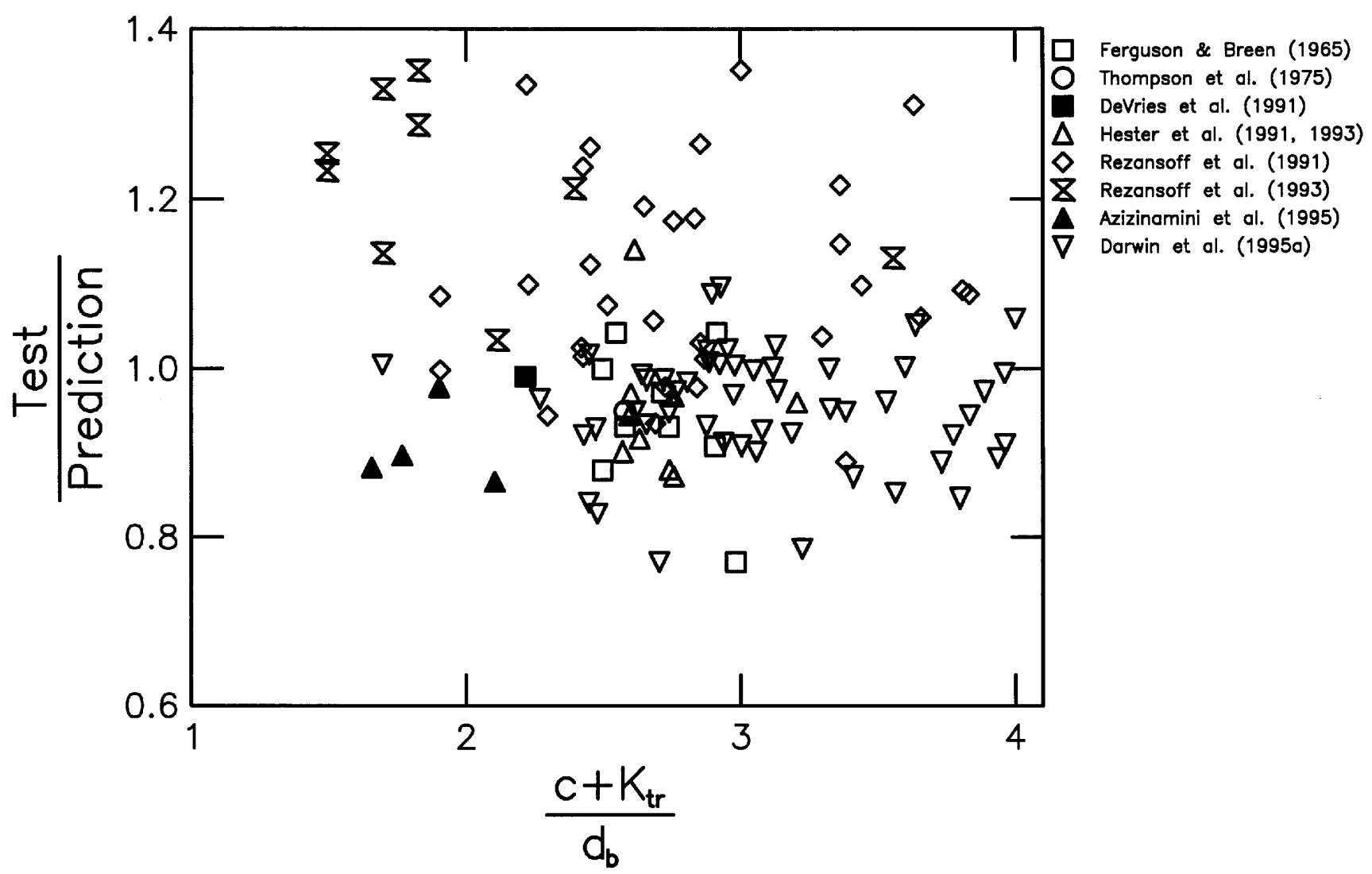

Fig. 4-Test/prediction ratio versus $\left(c+K_{t r}\right) / d_{b}$ for 117 beams with $l_{d} / d_{b} \geq 16$ and $\left(c+K_{t r}\right) / d_{b} \leq 4\left(K_{t r}=35.3 t_{r} t_{d} A_{t r} / s n\right)$

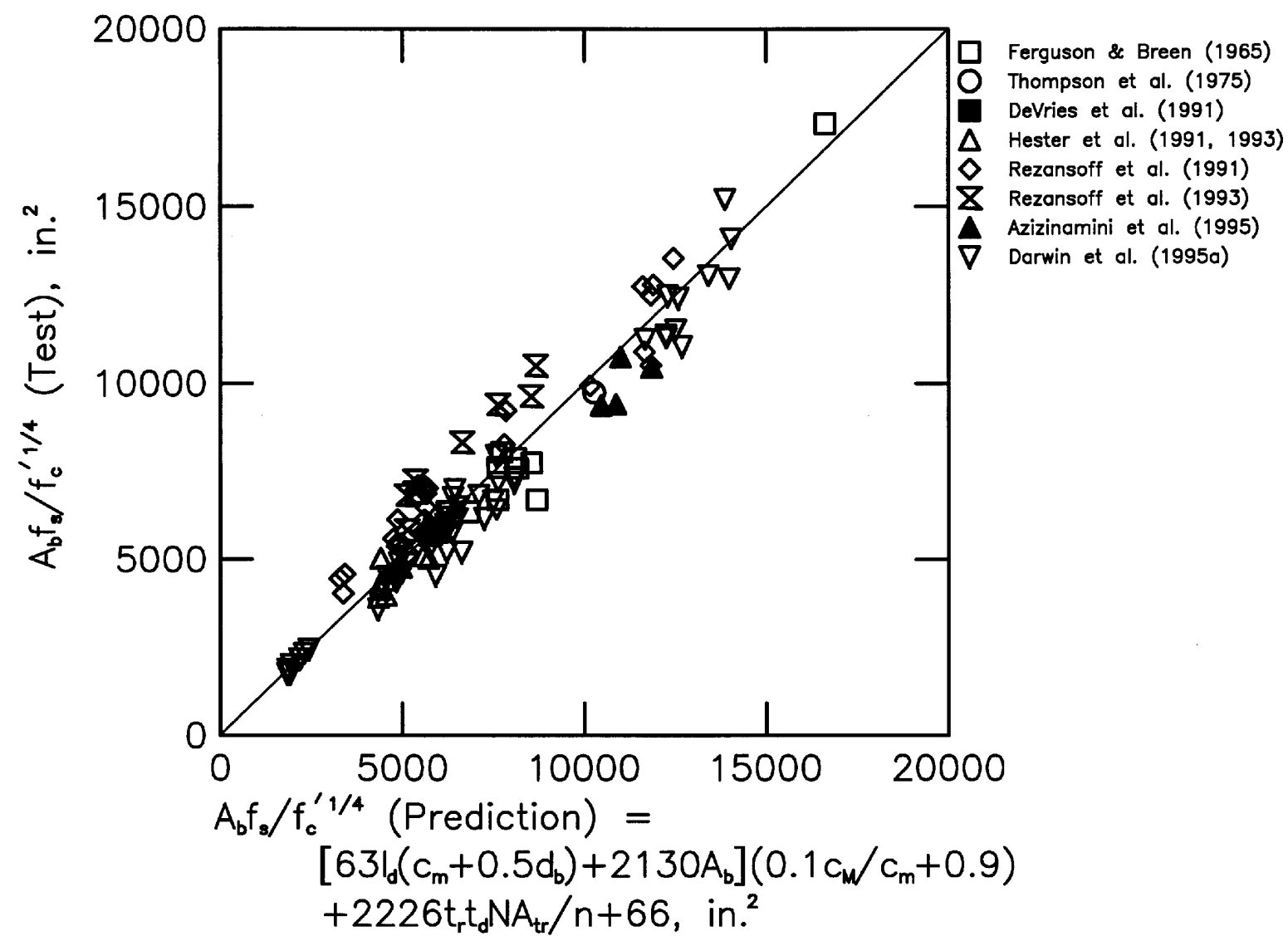

Fig. 5-Experimental bond force $T_{b}=A_{b} f_{s}$ normalized with respect to $f_{c}^{\prime 1 / 4}$ versus predicted bond force $A_{b} f_{s} / f_{c}^{\prime 1 / 4}$ for bars with confining reinforcement 
Eq. (4) for the 11 tests is 0.99 , with a COV of 0.107 , comparing favorably to the mean of 1.00 and COV of 0.107 for the full set of data. Of the 119 bars used to develop Eq. (17), bars yielded in 20 specimens prior to bond failure. For those tests, the mean test/prediction ratio is 1.15 , with a COV of 0.134 , comparing very favorably with the mean of 1.01 and $\mathrm{COV}$ of 0.125 for the full set of 119 specimens. For the 99 tests with bars confined by transverse reinforcement that did not yield, the mean test/prediction ratio using Eq. (17) is 0.98, with a COV of 0.100

Overall, the data indicates that, if the development/splice length is long enough to cause the bar to yield, yielding has no effect on the bond strength of bars not confined by transverse reinforcement, and results in an increase in bond strength for bars that are confined by transverse reinforcement. The increase for bars with confining reinforcement may result from a more uniform state of bond stress along the length of the bar due to greater slip that accompanies yielding. This greater slip mobilizes clamping stresses in the transverse reinforcement along a greater length of the bar.

\section{DESIGN EXPRESSIONS FOR DEVELOPMENT/ SPLICE LENGTH}

\section{Strength reduction $(\phi)$ factor}

Eq. (17) through (19) serve as the basis for design expressions for development/splice length. Eq. (18) and (19) cannot be used directly in design to calculate $l_{d}$ because they are based on the best-fit (average) expression, Eq. (17). If used as presented, bond strength would be below the value predicted by Eq. (17) 50 percent of the time. Procedures exist, however, for insuring an adequate level of safety through the selection of a strength reduction factor $(\phi)$ based on the desired level of reliability.

Following the procedures of Ellingwood, Galambos, MacGregor, and Cornell (1980), Mirza and MacGregor (1986), and Lundberg (1993), a ( $\phi)$ factor of 0.9 for development and splice strength has been obtained using a reliability index $\beta$ of 3.5 (Darwin et al. 1995c, 1996b). This gives an overall probability of bond failure equal to about one-fifth of the probability of a flexural failure, for which $\beta=3.0$ is normally obtained (Ellingwood et al. 1980). $\phi=0.9$ is obtained using Eq. (17) without the final term 66 as the design strength and Eq. (17) with the final term (if transverse reinforcement is used) as the predicted strength. Additional simplifications of Eq. (17), setting $c_{M}=c_{m}$ and dropping $0.25 \mathrm{in}$. from the definition of $c_{s}$, produce higher values of $\phi$ (Darwin et al. 1995c, 1996b).

$\phi=0.9$ for bond is applied in addition to the $\phi$ factor for the main load effect (e.g., 0.9 for flexure or 0.7 for tied columns) that is used to select the area and strength of the steel. Therefore, the total $\phi$ factor against a primary mode of failure in bond is the product of 0.9 and the $\phi$ factor for the main load effect.

In addition to allowing the selection of a desired relative probability of failure, using a reliability-based $\phi$ factor provides another important benefit. Since 87 percent of the tests in the database used to calculate $\phi$ are splice tests in which all of the bars are spliced at one location (a Class B splice in ACI 318-95 and a Class C splice in AASHTO Highway 1992), $\phi=0.9$ and Eq. (17) through (19) are already calibrated based on splice strength. Therefore, values of $l_{d}$ calculated using $\phi=0.9$ apply directly to spliced bars, removing the requirement to multiply development length by 1.3 to obtain the length of a Class B splice (ACI 318-95) or by 1.7 to obtain the length of a Class C splice (AASHTO Highway 1992).

The process of obtaining the design expressions that are presented in the following starts with the incorporation of $\phi$ on the right side of Eq. (17) (without the final term 66) and the substitution of the bar yield strength $f_{y}$ for $f_{s}$ on the left side

$$
\begin{aligned}
& \frac{A_{b} f_{y}}{f_{c}^{\prime 1 / 4}}=\phi\left\{\left[63 l_{d}\left(c_{m}+0.5 d_{b}\right)+2130 A_{b}\right]\right. \\
& \left.\left(0.1 \frac{c_{M}}{c_{m}}+0.9\right)+2226 t_{r} t_{d} \frac{N A_{t r}}{n}\right\}
\end{aligned}
$$

\section{Design expressions}

Using the formulation shown in Eq. (20), a detailed design expression in the form of Eq. (19) becomes

$$
\frac{l_{d}}{d_{b}}=\frac{\frac{f_{y}}{\phi f_{c}^{\prime 1 / 4}}-2130\left(0.1 \frac{c_{M}}{c_{m}}+0.9\right)}{80.2\left(\frac{c+K_{t r}}{d_{b}}\right)}
$$

in which

$c=\left(c_{m}+0.5 d_{b}\right)\left(0.1 c_{M} / c_{m}+0.9\right)$ and $c_{m}, c_{M}, c_{s}, c_{s i}, c_{s o}$, and $c_{b}$ are defined following Eq. (3).

$K_{t r}=K_{t r}$ (conv. $)=34.5 t_{d} A_{t r} / s n=34.5\left(0.72 d_{b}+0.28\right) A_{t r} / s n$ for conventional bars (average $R_{r}=0.0727$ )

$K_{t r}=K_{t r}($ new $)=53 t_{d} A_{t r} / s n=53\left(0.72 d_{b}+0.28\right) A_{t r} / s n$ for high relative rib area bars (average $R_{r}=0.1275$ )

$\left(c+K_{t r}\right) / d_{b} \leq 4.0$

Incorporating $\phi=0.9$ into Eq. (21) and conservatively rounding the coefficients gives

$$
\frac{l_{d}}{d_{b}}=\frac{\frac{f_{y}}{f_{c}^{\prime 1 / 4}}-1900\left(0.1 \frac{c_{M}}{c_{m}}+0.9\right)}{72\left(\frac{c+K_{t r}}{d_{b}}\right)}
$$

Eq. (22) is the prototype for design equations based on Eq. (20). Different degrees of simplification are possible, depending on the application and the level of simplification desired.

One such simplification can be obtained by setting $c_{M} / c_{m}=1$

$$
\frac{l_{d}}{d_{b}}=\frac{\frac{f_{y}}{f_{c}^{\prime 1 / 4}}-1900}{72\left(\frac{c+K_{t r}}{d_{b}}\right)}
$$

in which $c=\left(c_{m}+0.5 d_{b}\right)$.

In applying Eq. (23) to design, it would seem prudent to change the definition of $c$ to the smaller of the cover to the center of the bar or one-half of the center-to-center bar spac- 
ing. The only change that this entails is dropping 0.25 in. from the definition of $c_{s}$ that follows Eq. (3). The definitions of $K_{t r}$ following Eq. (21) remain unchanged.

Following the lead of ACI 318-95, an alternate simplification of Eq. (22), for the case in which the clear spacing between bars being developed or spliced is not less than $2 d_{b}$ and the cover is not less than $d_{b}$ [i.e., $\left(c+K_{t r}\right) / d_{b} \geq 1.5$ ], is obtained by setting $\left(c+K_{t r}\right) / d_{b}=1.5$.

This gives

$$
\frac{l_{d}}{d_{b}}=\frac{\frac{f_{y}}{f_{c}^{\prime 1 / 4}}-1900}{108}
$$

Since, except for shells, the minimum cover $c_{b}$ for cast-inplace concrete is $0.75 \mathrm{in}$. (19 $\mathrm{mm})$ and the minimum clear spacing $2 c_{s i}$ is 1 in. (25 mm) (ACI 318-95), Eq. (24) provides the maximum value of $l_{d}$ for No. 6 and smaller bars.

For bars with a cover not less than $d_{b}$ and a clear spacing not less than $7 d_{b}$ (principally slabs), Eq. (22) can be conservatively simplified to

$$
\frac{l_{d}}{d_{b}}=\frac{\frac{f_{y}}{f_{c}^{\prime 1 / 4}}-1900}{135}
$$

$l_{d}$ from Eq. (25) is 80 percent of $l_{d}$ calculated using Eq. (24). Because of the simplified format, neither Eq. (24) nor Eq. (25) takes advantage of the higher value of $K_{t r}$ provided by high relative rib area bars. Like the simplified format in ACI 318-95 (discussed in the next section), each of the two equations provides a single value of $l_{d} / d_{b}$ for each combination of $f_{y}$ and $f_{c}^{\prime}$.

\section{Comparison with current design criteria}

To illustrate the effects on development and splice lengths of both the newly proposed expressions and high relative rib area bars, values of $l_{d}$ obtained with Eq. (22) through (25) are compared with development and splice lengths calculated under the provisions of ACI 318-95. Comparisons are limited to uncoated bottom-cast bars.

Eq. (22) through (25) differ from current design criteria in several important respects.

1. The relationship between $l_{d}$ and the steel stress $f_{s}$ or $f_{y}$ is linear but nonproportional, rather than proportional, as in current design expressions. The more accurate representation provided by Eq. (22) through (25) results in values of $l_{d}$ that are relatively shorter for $f_{y}<60 \mathrm{ksi}(414 \mathrm{MPa})$ and relatively longer for $f_{y}>60 \mathrm{ksi}(414 \mathrm{MPa})$ than obtained with ACI 318-95. Eq. (22) through (25) automatically account for the fact that, when $f_{y}$ is increased by 25 percent from 60 to $75 \mathrm{ksi}$ (414 to $517 \mathrm{MPa}$ ), $l_{d}$ must be increased by more than 25 percent.

2. The effect of concrete strength on bond strength is represented by $f_{c}^{\prime}{ }^{1 / 4}$ rather than $f_{c}^{\prime 1 / 2}$. The impact of this change is greatest for high-strength concrete. The proposed expressions apply up to at least $16,000 \mathrm{psi}(110 \mathrm{MPa})$; the development length expressions in ACI 318-95 limit $f_{c}^{\prime}{ }^{1 / 2}$ to $100 \mathrm{psi}(0.69$ $\mathrm{MPa})$, corresponding to $f_{c}^{\prime}=10,000 \mathrm{psi}(69 \mathrm{MPa})$.

3. Using Eq. (22) through (25), splice length and development length are identical, removing the requirement to multiply $l_{d}$ by 1.3 (ACI) or 1.7 (AASHTO) to obtain the length of most splices.

The key aspects of the development/splice length criteria of ACI 318-95 are summarized next.

ACI 318-95-Under the provisions of ACI 318-95, two options are available for selecting development length. One involves a chart with selected expressions for $l_{d} / d_{b}$, and the other involves the use of a more detailed expression for $l_{d} / d_{b}$. Under Section 12.2.2 for bottom-cast uncoated reinforcement, $l_{d} / d_{b}=f_{y} /\left(25 f_{c}^{\prime}{ }^{1 / 2}\right)$ for No. 6 and smaller bars and $f_{y} /\left(20 f_{c}^{\prime}{ }^{1 / 2}\right)$ for No. 7 and larger bars if the bars have a clear spacing between bars $\geq d_{b}$, cover $\geq d_{b}$, and transverse reinforcement is not less than the code minimums, or clear spacing between bars $\geq 2 d_{b}$ and cover $\geq d_{b}$. For all other cases, $l_{d} /$ $d_{b}=3 f_{y} /\left(50 f_{c}^{\prime}{ }^{1 / 2}\right)$ for No. 6 and smaller bars and $3 f_{y} /\left(40 f_{c}^{\prime}{ }^{1 / 2}\right)$ for No. 7 and larger bars.

Under Section 12.2.3

$$
\frac{l_{d}}{d_{b}}=\frac{3}{40} \frac{f_{y}}{f_{c}^{\prime 1 / 2}\left(\frac{c+K_{t r}}{d_{b}}\right)}
$$

in which $K_{t r}=A_{t r} f_{y t} /(1500 s n),\left(c+K_{t r}\right) / d_{b} \leq 2.5$. Although $K_{t r}$ is the same symbol as used in this study to represent the effect of transverse reinforcement, the value includes $f_{y t}$ and does not correspond to the value in Eq. (21) through (23).

When 50 percent or less of the reinforcement is spliced at one location and the area of steel provided is equal to or greater than twice the area required, the splice length is equal to $1.3 l_{d}$.

Bars not confined by transverse reinforcement-For bars not confined by transverse reinforcement, it is appropriate to compare the simplified expressions in ACI 318-95 with the development and splice lengths obtained using Eq. (24) and (25). For No. 7 (22-mm) bars and larger with clear spacing $\geq$ $2 d_{b}$ and cover $\geq d_{b}$ and $4000 \mathrm{psi}(28 \mathrm{MPa})$ concrete, $l_{d} / d_{b}$ is 47.4 for developed bars and 61.7 for Class B splices, under the provisions of ACI 318-95, and 52.26 using Eq. (24) for both developed and spliced bars. Thus, using the proposed expression, the development length is 10 percent greater than under the provisions of ACI 318-95, while the splice length is 18 percent lower. The same percentages hold for the conditions under which Eq. (25) is applied. Overall, for normal-strength concretes, Eq. (24) and (25) result in greater development lengths and shorter splice lengths than do the provisions of Section 12.2.2 of ACI 318-95. The increases in development length are more than matched by the reductions in splice length.

Comparisons of development and splice lengths obtained using Eq. (22) and (23) with the more detailed provisions of ACI 318-95 [Eq. (26)] are summarized in Table 2 for the 35 beam configurations used by Darwin et al. (1995c, $1996 b)$ to develop the reliability-based $\phi$ factor [the detailed comparisons are presented by Darwin et al. (1995b) 
and in Appendix B]. ${ }^{*}$ The tables cover concrete compressive strengths of 3000,4000 , and $6000 \mathrm{psi}(21,28$, and $41 \mathrm{MPa})$ for developed or spliced No. 6, No. 8, No. 10, and No. 11 $(19,25,32$, and 36-mm) bars. Comparisons show that development lengths obtained with Eq. (23) (the more simplified of the two new expressions) are, on average, 114 percent of those obtained with ACI 318-95. Development lengths obtained with Eq. (22) are, on average, 102 percent of those obtained with the Code. The splice lengths obtained with Eq. (23) average 88 percent of those obtained with ACI 318-95, while those obtained with Eq. (22) average 78 percent of those obtained with the Code. These comparisons show that Eq. (22) and (23) result in a small increase in development length and a substantial reduction in splice length compared to values obtained under the provisions of ACI 318-95.

Bars confined by transverse reinforcement-Comparisons of development and splice lengths obtained using Eq. (22) and (23) with those obtained under the provisions of ACI 318-95 are summarized in Table 2 for the 140 beams with transverse reinforcement used to develop $\phi=0.9$ (Darwin et al. 1995c, 1996b) [the detailed comparisons are presented by Darwin et al. (1995b) and in Appendix B]. Comparisons include development lengths obtained with both conventional and high relative rib area reinforcement. Results in Table 2 show the following.

Effect of relative rib area. Limiting consideration to the effect of using high relative rib area bars (a savings not available under ACI 318-95), the average ratios of $l_{d}$ for high relative rib area bars to $l_{d}$ for conventional bars are 0.87 and 0.84 using Eq. (22) and (23), respectively. Therefore, depending on the expression used for the design, average reductions of 13 to 16 percent in development and splice length can be expected with the use of high relative rib area bars.

Comparisons with ACI 318-95. For conventional reinforcement, the development lengths average 95 and 116 percent for Eq. (22) and (23), respectively, of those obtained using ACI 318-95; the splice lengths average 73 and 89 percent, respectively. For high relative rib area bars, the development lengths obtained with Eq. (22) and (23) average 83 and 97 percent, respectively, of the development lengths obtained with ACI 318-95; the splice lengths average 64 and 75 percent, respectively, of the splice lengths obtained with ACI 318-95. Overall, significant savings can be obtained with a conversion to the new expressions. Even higher savings are available when Eq. (22) and (23) are used in conjunction with high relative rib area bars.

\section{SUMMARY AND CONCLUSIONS}

Test results for 133 splice and development specimens in which the bars are not confined by transverse reinforcement and 166 specimens in which the bars are confined by transverse reinforcement are used to develop an expression for the bond force at failure as a function of concrete strength, cover, bar spacing, development/splice length, transverse reinforcement, and the geometric properties of the developed/ spliced bars. The expression is valid for concrete strengths

*The Appendix is available in xerographic or similar form from ACI headquarters, where it will be kept permanently on file, at a charge equal to the cost of reproduction plus handling at time of request. between 2500 and 16,000 psi (17 and $110 \mathrm{MPa}$ ). Results are used to formulate design criteria that incorporate a reliability-based strength reduction $(\phi)$ factor that allows the calculation of a single value for both development and splice length for given material properties and member geometry.

The following conclusions are based on the analyses and comparisons made in this paper.

1. The relationship between bond force and development or splice length $l_{d}$ is linear but not proportional. Thus, to increase the bond force (or bar stress) by a given percentage requires more than the percentage increase in $l_{d}$.

2. $f_{c}^{\prime}{ }^{1 / 2}$ does not provide an accurate representation of the effect of concrete strength on bond strength over the full range of concrete strengths in use today. Development/splice strengths are underestimated for low-strength concretes and overestimated for high-strength concretes.

3. $f_{c}^{\prime}{ }^{1 / 4}$ provides an accurate representation of the effect of concrete strength on bond strength for concretes with compressive strengths between 2500 and 16,000 psi (17 and $110 \mathrm{MPa}$ ).

4. The most accurate representation of the effect of transverse reinforcement on bond strength obtained in the current analysis includes parameters that account for the number of transverse reinforcing bars that cross the developed/spliced bar, the area of the transverse reinforcement, the number of bars developed or spliced at one location, the relative rib area of the developed/spliced bar, and the size of the developed/ spliced bar.

5. The yield strength of transverse reinforcement plays no significant role in the effectiveness of the transverse reinforcement in improving development/splice strength.

6. Depending on the design expression selected:

a. For bars that are not confined by transverse reinforcement, development lengths average 2 to 14 percent higher than those obtained using ACI 318-95, and splice lengths

\section{Table 2-Ratios of development and splice lengths obtained using proposed expressions to development and splice lengths obtained using ACI 318-95}

\begin{tabular}{|c|c|c|c|c|c|}
\hline & & \multicolumn{2}{|c|}{$\begin{array}{l}\text { Development } \\
\text { lengths }\end{array}$} & \multicolumn{2}{|c|}{ Splice lengths } \\
\hline & & $\begin{array}{l}\text { Eq. (22) } \\
\text { ACI } 95\end{array}$ & $\begin{array}{l}\text { Eq. (23) } \\
\text { ACI 95 }\end{array}$ & $\begin{array}{l}\text { Eq. (22) } \\
\text { ACI 95 }\end{array}$ & $\begin{array}{l}\text { Eq. (23) } \\
\text { ACI 95 }\end{array}$ \\
\hline $\begin{array}{l}35 \text { beams without } \\
\text { transverse } \\
\text { reinforcement }\end{array}$ & $\begin{array}{l}\text { Minimum } \\
\text { Maximum } \\
\text { Average }\end{array}$ & $\begin{array}{l}0.785 \\
1.176 \\
1.017\end{array}$ & $\begin{array}{l}1.036 \\
1.377 \\
1.141\end{array}$ & $\begin{array}{l}0.604 \\
0.904 \\
0.782\end{array}$ & $\begin{array}{l}0.797 \\
1.059 \\
0.878\end{array}$ \\
\hline $\begin{array}{c}140 \text { beams with } \\
\text { transverse } \\
\text { reinforcement, } \\
\text { conv. bars }\end{array}$ & $\begin{array}{l}\text { Minimum } \\
\text { Maximum } \\
\text { Average }\end{array}$ & $\begin{array}{l}0.776 \\
1.270 \\
0.951\end{array}$ & $\begin{array}{l}0.832 \\
1.730 \\
1.156\end{array}$ & $\begin{array}{l}0.597 \\
0.977 \\
0.732\end{array}$ & $\begin{array}{l}0.640 \\
1.331 \\
0.889\end{array}$ \\
\hline $\begin{array}{l}140 \text { beams with } \\
\text { transverse } \\
\text { reinforcement, } \\
\text { high } R_{r} \text { bars }{ }^{\dagger}\end{array}$ & $\begin{array}{c}\text { Minimum } \\
\text { Maximum } \\
\text { Average }\end{array}$ & $\begin{array}{l}0.622 \\
1.127 \\
0.826\end{array}$ & $\begin{array}{l}0.719 \\
1.405 \\
0.973\end{array}$ & $\begin{array}{l}0.479 \\
0.867 \\
0.635\end{array}$ & $\begin{array}{l}0.553 \\
1.081 \\
0.749\end{array}$ \\
\hline & & \multicolumn{4}{|c|}{ Development and splice lengths } \\
\hline & & \multicolumn{2}{|c|}{$\begin{array}{l}\operatorname{High} R_{r}^{\dagger} \\
\text { Conv. } \\
{[\text { Eq. }(22)]}\end{array}$} & \multicolumn{2}{|c|}{$\begin{array}{l}\text { High } R_{r}^{\dagger} \\
{ }^{*} \\
\text { Conv. } \\
\text { [Eq. }(23)]\end{array}$} \\
\hline $\begin{array}{l}140 \text { beams with } \\
\text { transverse } \\
\text { reinforcement }\end{array}$ & $\begin{array}{c}\text { Minimum } \\
\text { Maximum } \\
\text { Average }\end{array}$ & \multicolumn{2}{|c|}{$\begin{array}{l}0.779 \\
1.000 \\
0.867\end{array}$} & \multicolumn{2}{|c|}{$\begin{array}{l}0.753 \\
1.000 \\
0.842\end{array}$} \\
\hline
\end{tabular}


average 12 to 22 percent lower than those obtained with ACI 318-95 for Class B splices (i.e., for a 1.3 modification factor).

b. For conventional bars confined by transverse reinforcement, development lengths average 5 percent lower to 16 percent higher than those obtained using ACI 318-95, while splice lengths average 11 to 27 percent lower than those obtained with ACI 318-95 for Class B splices.

c. For high relative rib area bars confined by transverse reinforcement, development lengths average 3 to 17 percent lower than those obtained using ACI 318-95, while splice lengths average 25 to 36 percent lower than those obtained with ACI 318-95. When confined by transverse reinforcement, high relative rib area bars require development and splice lengths that are 13 to 16 percent lower than required by conventional bars.

\section{ACKNOWLEDGMENTS}

Support for this research was provided by the Civil Engineering Research Foundation under CERF Contract No. 91-N6002, the National Science Foundation under NSF Grants No. MSS-9021066 and CMS-9402563, the U.S. Department of Transportation, Federal Highway Administration, the Reinforced Concrete Research Council under RCRC Project 56, ABC Coating, Inc., Birmingham Steel Corp., Chaparral Steel Co., Fletcher Coating Co., Florida Steel Corp., Morton Powder Coatings, Inc., North Star Steel Co., O'Brien Powder Products, Inc., and 3M Corp. Support was also provided by Geiger Ready-Mix, Iron Mountain Trap Rock Co., and Richmond Screw Anchor Co.

$A_{b}=$ bar area, in. ${ }^{2}$

$A_{t r}=$ area of each stirrup or tie crossing potential plane of splitting adjacent to reinforcement being developed or spliced, in. $^{2}$

$c \quad=\quad c_{m}+0.5 d_{b}$

$c_{b}=$ bottom cover of reinforcing bars, in.

$c_{M}=$ maximum value of $c_{s}$ or $c_{b}\left(c_{M} / c_{m} \leq 3.5\right)$, in.

$c_{m}=$ minimum value of $c_{s}$ or $c_{b}\left(c_{M} / c_{m} \leq 3.5\right)$, in.

$c_{s}=\min (\mathrm{csi}+0.25$ in., cso $)$ or $\min (\mathrm{csi}, \mathrm{cso})$, in.

$c_{s i}=$ one-half of clear spacing between bars, in.

$c_{\text {so }}=$ side cover of reinforcing bars, in.

$d_{b}=$ nominal bar diameter, in.

$f_{\mathcal{F}}^{\prime}=$ concrete compressive strength, psi; $f_{c}^{\prime}{ }^{1 / 2}$ and $f_{c}^{\prime}{ }^{1 / 4}$, psi

$f_{c}^{\mathcal{F}} p=$ concrete compressive strength to power $p$, psi

$f_{s} \quad=\quad$ steel stress at failure, psi

$f_{y}=$ yield strength of bars being spliced or developed, psi

$f_{y t}=$ yield strength of transverse reinforcement, in psi

$K_{t r}=$ term representing effect of transverse reinforcement onsbremgth. Value depends on stage of analysis and design expression in which it is used. $K_{t r}=29.6 t_{r} t_{d} A_{t r} / s n$ based on initial analysis. $K_{t r}=35.3 t_{r} t_{d} / A_{t r} / s n$ based on final analysis $\left[K_{t r}\right.$ (conv.) $=34.5$ $\left(0.72 d_{b}+0.28\right) A_{t r} / s n$ for conventional reinforcement (average $\left.R_{r}=0.0727\right) ; K_{t r}($ new $)=53\left(0.72 d_{b}+0.28\right) A_{t r} / s n$ for new reinforcement (average $\left.R_{r}=0.1275\right)$ ]

$=A_{t r} f_{y t} /(1500 s n)$ in ACI 318-95

$l_{d}=$ development or splice length, in.

$N=$ number of transverse reinforcing bars (stirrups or ties) crossing

$n=$ number of bars being developed or spliced along plane of splitting

$R_{r}=\quad$ ratio of projected rib area normal to bar axis to product of nominal bar perimeter and center-to-center rib spacing

$s=$ spacing of transverse reinforcement, in.
$T_{b}=\quad$ total force in bar at splice failure, $\mathrm{lb}$

$T_{c}=$ concrete contribution to total force in bar at splice failure, $\mathrm{lb}$

$T_{s}=$ confining steel contribution to total force in bar at splice failure, in $\mathrm{lb}$

$t_{d}=0.72 d_{b}+0.28$, term representing effect of bar size on $T_{s}$

$t_{r}=9.6 R_{r}+0.28$, term representing effect of relative rib area on $T_{s}$ $\beta=$ reliability index

$\phi=$ reliability-based strength reduction factor

\section{REFERENCES}

AASHTO Highway Subcommittee on Bridges and Structures, 1992. Standard Specifications for Highway Bridges, 15th Edition, American Association of State Highway and Transportation Officials, Washington, DC, $686 \mathrm{pp}$.

ACI Committee 318, 1989. Building Code Requirements for Reinforced Concrete (ACI 318-89) and Commentary-ACI 318R-89, American Concrete Institute, Detroit, $353 \mathrm{pp}$.

ACI Committee 318, 1995. Building Code Requirements for Reinforced Concrete (ACI 318-95) and Commentary-ACI 318R-95, American Concrete Institute, Detroit, $369 \mathrm{pp}$.

ACI Committee 408, 1990. Suggested Development, Splice, and Standard Hook Provisions for Deformed Bars in Tension (ACI 408.1R-90), American Concrete Institute, Detroit, 3 pp.

ASTM, 1994. "Standard Test Method for Compressive Strength of Cylindrical Concrete Specimens (ASTM C 39-93a)," 1994 Annual Book of ASTM Standards, V. 4.02, American Society of Testing and Materials, Philadelphia, pp. 17-21.

Azizinamini, A; Stark, M.; Roller, John J.; and Ghosh, S. K., 1993. "Bond Performance of Reinforcing Bars Embedded in High-Strength Concrete," ACI Structural Journal, V. 90, No. 5, Sept.-Oct., pp. 554-561.

Azizinamini, A; Chisala, M.; and Ghosh, S. K., 1995. "Tension Development Length of Reinforcing Bars Embedded in High-Strength Concrete," Engineering Structures. (in press)

Chamberlin, S. J., 1956. "Spacing of Reinforcement in Beams," ACI Journal, Proceedings V. 53, No. 1, July, pp. 113-134.

Chamberlin, S. J., 1958. "Spacing of Spliced Bars in Beams," ACI JOURNAL, Proceedings V. 54, No. 8, Feb., pp. 689-698.

Chinn, James; Ferguson, Phil M.; and Thompson, J. Neils, 1955. "Lapped Splices in Reinforced Concrete Beams," ACI Jou Rnal, Proceedings V. 52, No. 2, Oct., pp. 201-214.

Choi, Oan Chul; Hadje-Ghaffari, Hossain; Darwin, David; and McCabe, Steven L., 1990. "Bond of Epoxy-Coated Reinforcement to Concrete: Bar Parameters," SL Report No. 90-1, University of Kansas Center for Research, Lawrence, Jan., 43 pp.

Choi, Oan Chul; Hadje-Ghaffari, Hossain; Darwin, David; and McCabe, Steven L., 1991. "Bond of Epoxy-Coated Reinforcement: Bar Parameters," ACI Materials Journal, V. 88, No. 2, Mar.-Apr., pp. 207-217.

Darwin, David; McCabe, Steven L.; Idun, Emmanuel K.; and Schoenekase, Steve P., 1992a. "Development Length Criteria: Bars Without Transverse Reinforcement," SL Report 92-1, University of Kansas Center for Research, Lawrence, Apr., 62 pp.

Darwin, David; McCabe, Steven L.; Idun, Emmanuel K.; and Schoenekase, Steve P., 1992b. "Development Length Criteria: Bars Not Confined by Transverse Reinforcement," ACI Structural Journal, V. 89, No. 6, Nov.Dec., pp. 709-720.

Darwin, David, and Graham, Ebenezer K., 1993a. "Effect of Deformation Height and Spacing on Bond Strength of Reinforcing Bars," $S L$ Report 93-1, University of Kansas Center for Research, Lawrence, Jan., 68 pp.

Darwin, David, and Graham, Ebenezer K., 1993b. "Effect of Deformation Height and Spacing on Bond Strength of Reinforcing Bars," ACI Structural Journal, V. 90, No. 6, Nov.-Dec., pp. 646-657.

Darwin, David; Tholen, Michael L.; Idun, Emmanuel K.; and Zuo, Jun, 1995a. "Splice Strength of High Relative Rib Area Reinforcing Bars," $S L$ Report 95-3, University of Kansas Center for Research, Lawrence, May, 58 pp.

Darwin, D.; Zuo, Jun; Tholen, Michael L.; and Idun, Emmanuel K., 1995b. "Development Length Criteria for Conventional and High Relative Rib Area Reinforcing Bars," SL Report 95-4, University of Kansas Center for Research, Lawrence, May, 70 pp.

Darwin, David; Idun, Emmanuel K.; Zuo, Jun; and Tholen, Michael L., 1995c. "Reliability-Based Strength Reduction Factor for Bond," SL Report 95-5, University of Kansas Center for Research, Lawrence, May, 47 pp.

Darwin, David; Tholen, Michael L.; Idun, Emmanuel K.; and Zuo, Jun, 1996a. "Splice Strength of High Relative Rib Area Reinforcing Bars," ACI Structural Journal, V. 93, No. 1, Jan.-Feb., pp. 95-107.

Darwin, David; Idun, Emmanuel K.; Zuo, Jun; and Tholen, Michael L. 1996b. "Reliability-Based Strength Reduction Factor for Bond," ACI Structural Journal . (under review) 
DeVries, R. A.; Moehle, J. P.; and Hester, W., 1991. "Lap Splice Strength of Plain and Epoxy-Coated Reinforcement," Report No. UCB/ SEMM-91/02, University of California, Berkeley, Jan., 86 pp.

Ellingwood, Bruce; Galambos, Theodore V.; MacGregor, James G.; and Cornell, C. Allin, 1980. "Development of a Probability- Based Criterion for American National Standard A58," NBS Special Publication 577, U.S. Department of Commerce, Washington, DC, June, 222 pp.

Ferguson, Phil M., and Thompson, J. Neils, 1965. "Development Length of High-Strength Reinforcing Bars," ACI Journal, Proceedings V. 62, No. 1, Jan., pp. 71-94.

Ferguson, Phil M., and Breen, John E., 1965. "Lapped Splices for HighStrength Reinforcing Bars," ACI Journal, Proceedings V. 62, No. 9, Sept., pp. 1063-1078.

Harajli, M. H., 1994. "Development/Splice Strength of Reinforcing Bars Embedded in Plain and Fiber Reinforced Concrete," ACI Structural Journal, V. 91, No. 5, Sep.-Oct., pp. 511-520.

Hester, Cynthia J.; Salamizavaregh, Shahin; Darwin, David; and McCabe, Steven L., 1991. "Bond of Epoxy-Coated Reinforcement to Concrete: Splices," SL Report 91-1, University of Kansas Center for Research, Lawrence, May, 66 pp.

Hester, Cynthia J.; Salamizavaregh, Shahin; Darwin, David; and McCabe, Steven L., 1993. "Bond of Epoxy-Coated Reinforcement: Splices," ACI Structural Journal, V. 90, No. 1, Jan.-Feb., pp. 89-102.

Lundberg, Jane E., 1993. "Reliability of Composite Columns and Beam Columns," Structural Engineering Report No. 93-2, University of Minnesota, Minneapolis, June, 233 pp.

Maeda, M.; Otani, S.; and Aoyama, H., 1991. "Bond Splitting Strength in Reinforced Concrete Members," Transactions of the Japan Concrete Institute, V. 13, pp. 581-588.

Mathey, Robert, and Watstein, David, 1961. "Investigation of Bond in
Beam and Pullout Specimens With High-Yield Strength Deformed Bars," ACI Jou RnA L, Proceedings V. 32, No. 9, Mar., pp. 1071-1090.

Mirza, S. Ali, and MacGregor, James G., 1986. "Strength Variability of Bond of Reinforcing Bars in Concrete Beams," Civil Engineering Report Series No. CE-86-1, Lakehead University, Thunder Bay, Ontario, Jan., 35 pp.

Orangun, C. O.; Jirsa, J. O.; and Breen, J. E., 1975. "Strength of Anchored Bars: A Re-Evaluation of Test Data on Development Length and Splices," Research Report No. 154-3F, Center for Highway Research, University of Texas at Austin, Jan., 78 pp.

Orangun, C. O.; Jirsa, J. O.; and Breen, J. E., 1977. "Re-Evaluation of Test Data on Development Length and Splices," ACI JOU RNAL, Proceedings V. 74, No. 3, Mar., pp. 114-122.

Rezansoff, T.; Konkankar, U. S.; and Fu, Y. C., 1991. "Confinement Limits for Tension Lap Splices under Static Loading," Report, University of Saskatchewan, Saskatoon, Aug., 24 pp.

Rezansoff, T.; Akanni, A; and Sparling, B., 1993. "Tensile Lap Splices under Static Loading: Review of the Proposed ACI 318 Code Provisions," ACI Structural Journal, V. 90, No. 4, July-Aug., pp. 374-384.

Sakurada, T; Morohashi, N.; and Tanaka, R., 1993. "Effect of Transverse Reinforcement on Bond Splitting Strength of Lap Splices," Transactions of the Japan Concrete Institute, V. 15, pp. 573-580.

Thompson, M. A.; Jirsa, J. O.; Breen, J. E.; and Meinheit, D. F., 1975. "Behavior of Multiple Lap Splices in Wide Sections," Research Report No. 154-1, Center for Highway Research, University of Texas at Austin, Feb., 75 pp.

Zekany, A. J.; Neumann, S.; and Jirsa, J. O., 1981. "Influence of Shear on Lapped Splices in Reinforced Concrete," Research Report No. 242-2, Center for Transportation Research, Bureau of Engineering Research, University of Texas at Austin, July, 88 pp. 